\title{
Strong Convergence Theorems for a Finite Family of $\lambda_{i}$-Strict Pseudocontractions in 2-Uniformly Smooth Banach Spaces by Metric Projections
}

\author{
Xin-dong Liu, ${ }^{1}$ Shih-sen Chang, ${ }^{2}$ and Xiong-rui Wang ${ }^{1}$ \\ ${ }^{1}$ School of Mathematics, Yibin University, Sichuan, Yibin 644007, China \\ ${ }^{2}$ College of Statistics and Mathematics, Yunnan University of Finance and Economics, Kunming, \\ Yunnan 650221, China \\ Correspondence should be addressed to Xin-dong Liu, 1xdemail@126.com \\ and Shih-sen Chang, changss@yahoo.cn
}

Received 16 July 2012; Accepted 27 August 2012

Academic Editor: Nan-Jing Huang

Copyright (C) 2012 Xin-dong Liu et al. This is an open access article distributed under the Creative Commons Attribution License, which permits unrestricted use, distribution, and reproduction in any medium, provided the original work is properly cited.

\begin{abstract}
A new hybrid projection algorithm is considered for a finite family of $\lambda_{i}$-strict pseudocontractions. Using the metric projection, some strong convergence theorems of common elements are obtained in a uniformly convex and 2-uniformly smooth Banach space. The results presented in this paper improve and extend the corresponding results of Matsushita and Takahshi, 2008, Kang and Wang, 2011, and many others.
\end{abstract}

\section{Introduction}

Let $E$ be a real Banach space and let $E^{*}$ be the dual spaces of $E$. Assume that $J$ is the normalized duality mapping from $E$ into $2^{E^{*}}$ defined by

$$
J(x)=\left\{x^{*} \in E^{*}:\left\langle x, x^{*}\right\rangle=\|x\|^{2}=\left\|x^{*}\right\|^{2}\right\}, \quad \forall x \in E,
$$

where $\langle\cdot, \cdot\rangle$ is the generalized duality pairing between $E$ and $E^{*}$.

Let $C$ be a closed convex subset of a real Banach space $E$. A mapping $T: C \rightarrow C$ is said to be nonexpansive if

$$
\|T x-T y\| \leq\|x-y\|,
$$


for all $x, y \in C$. Also a mapping $T: C \rightarrow C$ is called a $\lambda$-strict pseudocontraction if there exists a constant $\lambda \in(0,1)$ such that for every $x, y \in C$ and for some $j(x-y) \in J(x-y)$, the following holds:

$$
\langle T x-T y, j(x-y)\rangle \leq\|x-y\|^{2}-\lambda\|(I-T) x-(I-T) y\|^{2} .
$$

From (1.3) we can prove that if $T$ is $\lambda$-strict pseudo-contractive, then $T$ is Lipschitz continuous with the Lipschitz constant $L=(1+\lambda) / \lambda$.

It is well-known that the classes of nonexpansive mappings and pseudocontractions are two kinds important nonlinear mappings, which have been studied extensively by many authors (see [1-8]).

In [9] Reich considered the Mann iterative scheme $\left\{x_{n}\right\}$

$$
x_{n+1}=\left(1-\alpha_{n}\right) x_{n}+\alpha_{n} T x_{n}, \quad x_{1} \in C
$$

for nonexpansive mappings, where $\left\{\alpha_{n}\right\}$ is a sequence in $(0,1)$. Under suitable conditions, the author proved that $\left\{x_{n}\right\}$ converges weakly to a fixed point of T. In 2005, Kim and Xu [10] proved a strong convergence theorem for nonexpansive mappings by modified Mann iteration. In 2008, Zhou [11] extended and improved the main results of Kim and Xu to the more broad 2-uniformly smooth Banach spaces for $\lambda$-strict pseudocontractive mappings.

On the other hand, by using metric projection, Nakajo and Takahashi [12] introduced the following iterative algorithms for the nonexpansive mapping $T$ in the framework of Hilbert spaces:

$$
\begin{gathered}
x_{0}=x \in C, \\
y_{n}=\alpha_{n} x_{n}+\left(1-\alpha_{n}\right) T x_{n}, \\
C_{n}=\left\{z \in C:\left\|z-y_{n}\right\| \leq\left\|z-x_{n}\right\|\right\}, \\
Q_{n}=\left\{z \in C:\left\langle x_{n}-z, x-x_{n}\right\rangle \geq 0\right\}, \\
x_{n+1}=P_{C_{n} \cap Q_{n}} x, \quad n=0,1,2, \ldots,
\end{gathered}
$$

where $\left\{\alpha_{n}\right\} \subset[0, \alpha], \alpha \in[0,1)$, and $P_{C_{n} \cap Q_{n}}$ is the metric projection from a Hilbert space $H$ onto $C_{n} \cap Q_{n}$. They proved that $\left\{x_{n}\right\}$ generated by (1.5) converges strongly to a fixed point of $T$.

In 2006, Xu [13] extended Nakajo and Takahashi's theorem to Banach spaces by using the generalized projection.

In 2008, Matsushita and Takahashi [14] presented the following iterative algorithms for the nonexpansive mapping $T$ in the framework of Banach spaces:

$$
\begin{gathered}
x_{0}=x \in C, \\
C_{n}=\overline{\mathrm{co}}\left\{z \in C:\|z-T z\| \leq t_{n}\left\|x_{n}-T x_{n}\right\|\right\}, \\
D_{n}=\left\{z \in C:\left\langle x_{n}-z, J\left(x-x_{n}\right)\right\rangle \geq 0\right\}, \\
x_{n+1}=P_{C_{n} \cap D_{n}} x, \quad n=0,1,2, \ldots,
\end{gathered}
$$


where $\overline{\mathrm{co}} C$ denotes the convex closure of the set $C, J$ is normalized duality mapping, $\left\{t_{n}\right\}$ is a sequence in $(0,1)$ with $t_{n} \rightarrow 0$, and $P_{C_{n} \cap D_{n}}$ is the metric projection from $E$ onto $C_{n} \cap D_{n}$. Then, they proved that $\left\{x_{n}\right\}$ generated by (1.6) converges strongly to a fixed point of nonexpansive mapping $T$.

Recently, Kang and Wang [15] introduced the following hybrid projection algorithm for a pair of nonexpansive mapping $T$ in the framework of Banach spaces:

$$
\begin{gathered}
x_{0}=x \in C, \\
y_{n}=\alpha_{n} T_{1} x_{n}+\left(1-\alpha_{n}\right) T_{2} x_{n}, \\
C_{n}=\overline{c o}\left\{z \in C:\left\|z-T_{1} z\right\|+\left\|z-T_{2} z\right\| \leq t_{n}\left\|x_{n}-y_{n}\right\|\right\}, \\
x_{n+1}=P_{C_{n}} x, \quad n=0,1,2, \ldots,
\end{gathered}
$$

where $\overline{\mathrm{co}} C$ denotes the convex closure of the set $C,\left\{\alpha_{n}\right\}$ is a sequence in $[0,1],\left\{t_{n}\right\}$ is a sequence in $(0,1)$ with $t_{n} \rightarrow 0$, and $P_{C_{n}}$ is the metric projection from $E$ onto $C_{n}$. Then, they proved that $\left\{x_{n}\right\}$ generated by (1.7) converges strongly to a fixed point of two nonexpansive mappings $T_{1}$ and $T_{2}$.

In this paper, motivated by the research work going on in this direction, we introduce the following iterative for finding fixed points of a finite family of $\lambda_{i}$-strict pseudocontractions in a uniformly convex and 2-uniformly smooth Banach space:

$$
\begin{gathered}
x_{0}=x \in C, \\
y_{n}=\sum_{i=1}^{N} \alpha_{n, i} T_{i} x_{n}, \\
C_{n}=\overline{c o}\left\{z \in C: \sum_{i=1}^{N}\left\|z-T_{i} z\right\| \leq t_{n}\left\|x_{n}-y_{n}\right\|\right\}, \\
x_{n+1}=P_{C_{n}} x, \quad n=1,2, \ldots,
\end{gathered}
$$

where $\overline{\mathrm{CO} C}$ denotes the convex closure of the set $C,\left\{\alpha_{n, i}\right\}$ is $N$ sequences in $[0,1]$ and $\sum_{i=1}^{N} \alpha_{n, i}=1$ for each $n \geq 0,\left\{t_{n}\right\}$ is a sequence in $(0,1)$ with $t_{n} \rightarrow 0$, and $P_{C_{n}}$ is the metric projection from $E$ onto $C_{n}$. we prove defined by (1.8) converges strongly to a common fixed point of a finite family of $\lambda_{i}$-strictly pseudocontractions, the main results of Kang and Wang is extended and improved to strictly pseudocontractions.

\section{Preliminaries}

In this section, we recall the well-known concepts and results which will be needed to prove our main results. Throughout this paper, we assume that $E$ is a real Banach space and $C$ is a nonempty subset of $E$. When $\left\{x_{n}\right\}$ is a sequence in $E$, we denote strong convergence of $\left\{x_{n}\right\}$ to $x \in E$ by $x_{n} \rightarrow x$ and weak convergence by $x_{n} \rightarrow x$. We also assume that $E^{*}$ is the dual space of $E$, and $J: E \rightarrow 2^{E^{*}}$ is the normalized duality mapping. Some properties of duality mapping have been given in [16]. 
A Banach space $E$ is said to be strictly convex if $\|x+y\| / 2<1$ for all $x, y \in U=\{z \in$ $E:\|z\|=1\}$ with $x \neq y$. $E$ is said to be uniformly convex if for each $\epsilon>0$ there is a $\delta>0$ such that for $x, y \in E$ with $\|x\|,\|y\| \leq 1$ and $\|x-y\| \geq \epsilon,\|x+y\| \leq 2(1-\delta)$ holds. The modulus of convexity of $E$ is defined by

$$
\delta_{E}(\epsilon)=\inf \left\{1-\left\|\frac{x+y}{2}\right\|:\|x\|,\|y\| \leq 1,\|x-y\| \geq \epsilon\right\}
$$

$E$ is said to be smooth if the limit

$$
\lim _{t \rightarrow 0} \frac{\|x+t y\|-\|x\|}{t}
$$

exists for all $x, y \in U$. The modulus of smoothness of $E$ is defined by

$$
\rho_{E}(t)=\sup \left\{\frac{1}{2}(\|x+y\|+\|x-y\|)-1:\|x\| \leq 1,\|y\| \leq t\right\}
$$

A Banach space $E$ is said to be uniformly smooth if $\rho_{E}(t) / t \rightarrow 0$ as $t \rightarrow 0$. A Banach space $E$ is said to be $q$-uniformly smooth, if there exists a fixed constant $c>0$ such that $\rho_{E}(t) \leq c t^{q}$.

If $E$ is a reflexive, strictly convex, and smooth Banach space, then for any $x \in E$, there exists a unique point $x_{0} \in C$ such that

$$
\left\|x_{0}-x\right\|=\min _{y \in C}\|y-x\|
$$

The mapping $P_{C}: E \rightarrow C$ defined by $P_{C} x=x_{0}$ is called the metric projection from $E$ onto $C$. Let $x \in E$ and $u \in C$. Then it is known that $u=P_{C} x$ if and only if

$$
\langle u-y, J(x-u)\rangle \geq 0, \quad \forall y \in C .
$$

For the details on the metric projection, refer to [17-20].

In the sequel, we make use the following lemmas for our main results.

Lemma 2.1 (see [21]). Let E be a real 2-uniformly smooth Banach space with the best smooth constant $K$. Then the following inequality holds

$$
\|x+y\|^{2} \leq\|x\|^{2}+2\langle y, J(x)\rangle+2\|K y\|^{2}
$$

for any $x, y \in E$.

Lemma 2.2 (see [11]). Let $C$ be a nonempty subset of a real 2-uniformly smooth Banach space $E$ with the best smooth constant $K>0$ and let $T: C \rightarrow C$ be a $\lambda$-strict pseudocontraction. For $\alpha \in(0,1) \cap\left(0, \lambda / K^{2}\right]$, we define $T_{\alpha} x=(1-\alpha) x+\alpha T x$. Then $T_{\alpha}: C \rightarrow E$ is nonexpansive such that $F\left(T_{\alpha}\right)=F(T)$. 
Lemma 2.3 (demiclosed principle, see [22]). Let E be a real uniformly convex Banach space, let $C$ be a nonempty closed convex subset of $E$, and let $T: C \rightarrow C$ be a continuous pseudocontractive mapping. Then, $I-T$ is demiclosed at zero.

Lemma 2.4 (see [23]). Let $C$ be a closed convex subset of a uniformly convex Banach space. Then for each $r>0$, there exists a strictly increasing convex continuous function $\gamma:[0, \infty) \rightarrow[0, \infty)$ such that $\gamma(0)=0$ and

$$
r\left(\left\|T\left(\sum_{j=0}^{m} \mu_{j} z_{j}\right)-\sum_{j=0}^{m} \mu_{j} T z_{j}\right\|\right) \leq \max _{0 \leq j<k \leq m}\left(\left\|z_{j}-z_{k}\right\|-\left\|T z_{j}-T z_{k}\right\|\right),
$$

for all $m \geq 1,\left\{\mu_{j}\right\}_{j=0}^{m} \in \Delta^{m},\left\{z_{j}\right\}_{j=0}^{m} \subset C \cap B_{r}$, and $T \in \operatorname{Lip}(C, 1)$, where $\Delta^{m}=\left\{\left\{\mu_{0}, \mu_{1}, \ldots, \mu_{m}\right\}\right.$ : $0 \leq \mu_{j}(0 \leq j \leq m)$ and $\left.\sum_{j=0}^{m} \mu_{j}=1\right\}, B_{r}=\{x \in E:\|x\| \leq r\}$, and $\operatorname{Lip}(C, 1)$ is the set of all nonexpansive mappings from $C$ into $E$.

\section{Main Results}

Now we are ready to give our main results in this paper.

Lemma 3.1. Let $C$ be a closed convex subset of a uniformly convex and 2-uniformly smooth Banach space $E$ with the best smooth constant $K>0$, and $T: C \rightarrow C$ be a $\lambda$-strict pseudocontraction. Then for each $r>0$, there exists a strictly increasing convex continuous function $\gamma:[0, \infty) \rightarrow[0, \infty)$ such that $\gamma(0)=0$ and

$$
r\left(\alpha\left\|T\left(\sum_{j=0}^{m} \mu_{j} z_{j}\right)-\sum_{j=0}^{m} \mu_{j} T z_{j}\right\|\right) \leq \alpha \max _{0 \leq j<k \leq m}\left(\left\|z_{j}-T z_{j}\right\|+\left\|z_{k}-T z_{k}\right\|\right),
$$

for all $m \geq 1,\left\{\mu_{j}\right\}_{j=0}^{m} \in \Delta^{m},\left\{z_{j}\right\}_{j=0}^{m} \subset C \cap B_{r}$, where $\alpha \in(0,1) \cap\left(0, \lambda / K^{2}\right], \Delta^{m}=$ $\left\{\left\{\mu_{0}, \mu_{1}, \ldots, \mu_{m}\right\}: 0 \leq \mu_{j}(0 \leq j \leq m)\right.$ and $\left.\sum_{j=0}^{m} \mu_{j}=1\right\}, B_{r}=\{x \in E:\|x\| \leq r\}$.

Proof. Define the mapping $T_{\alpha}: C \rightarrow C$ as $T_{\alpha} x=(1-\alpha) x+\alpha T x$, for all $x \in C$. Then $T_{\alpha}$ is nonexpansive. From Lemma 2.4, there exists a strictly increasing convex continuous function $\gamma:[0, \infty) \rightarrow[0, \infty)$ with $\gamma(0)=0$ and such that

$$
r\left(\left\|T_{\alpha}\left(\sum_{j=0}^{m} \mu_{j} z_{j}\right)-\sum_{j=0}^{m} \mu_{j} T_{\alpha} z_{j}\right\|\right) \leq \max _{0 \leq j<k \leq m}\left(\left\|z_{j}-z_{k}\right\|-\left\|T_{\alpha} z_{j}-T_{\alpha} z_{k}\right\|\right) .
$$


Hence

$$
\begin{aligned}
r\left(\alpha\left\|T\left(\sum_{j=0}^{m} \mu_{j} z_{j}\right)-\sum_{j=0}^{m} \mu_{j} T z_{j}\right\|\right) & =r\left(\left\|T_{\alpha}\left(\sum_{j=0}^{m} \mu_{j} z_{j}\right)-\sum_{j=0}^{m} \mu_{j} T_{\alpha} z_{j}\right\|\right) \\
& \leq \max _{0 \leq j<k \leq m}\left(\left\|z_{j}-z_{k}\right\|-\left\|T_{\alpha} z_{j}-T_{\alpha} z_{k}\right\|\right) \\
& \leq \max _{0 \leq j<k \leq m}\left(\left\|z_{j}-T_{\alpha} z_{j}\right\|+\left\|z_{k}-T_{\alpha} z_{k}\right\|\right) \\
& =\alpha \max _{0 \leq j<k \leq m}\left(\left\|z_{j}-T z_{j}\right\|+\left\|z_{k}-T z_{k}\right\|\right) .
\end{aligned}
$$

This completes the proof.

Theorem 3.2. Let $C$ be a nonempty closed subset of a uniformly convex and 2-uniformly smooth Banach space $E$ with the best smooth constant $K>0$, assume that for each $i(i=1,2, \ldots, N), T_{i}$ : $C \rightarrow C$ is a $\lambda_{i}$-strict pseudocontraction for some $0<\lambda_{i}<1$ such that $\mathcal{F}=\cap_{i=1}^{N} \mathcal{F}\left(T_{i}\right) \neq \emptyset$. Let $\left\{\alpha_{n, i}\right\}$ be $N$ sequences in $[0,1]$ with $\sum_{i=1}^{N} \alpha_{n, i}=1$ for each $n \geq 0$ and $\left\{t_{n}\right\}$ be a sequence in $(0,1)$ with $t_{n} \rightarrow 0$. Let $\left\{x_{n}\right\}$ be a sequence generated by (1.8), where $\overline{\mathrm{co}}\left\{z \in C: \sum_{i=1}^{N}\left\|z-T_{i} z\right\| \leq t_{n}\left\|x_{n}-y_{n}\right\|\right\}$ denotes the convex closure of the set $\left\{z \in C: \sum_{i=1}^{N}\left\|z-T_{i} z\right\| \leq t_{n}\left\|x_{n}-y_{n}\right\|\right\}$ and $P_{C_{n}}$ is the metric projection from $E$ onto $C_{n}$. Then $\left\{x_{n}\right\}$ converges strongly to $P_{\mp} x$.

Proof. (I) First we prove that $\left\{x_{n}\right\}$ is well defined and bounded.

It is easy to check that $C_{n}$ is closed and convex and $\mathcal{F} \subset C_{n}$ for all $n \geq 0$. Therefore $\left\{x_{n}\right\}$ is well defined.

Put $p=P_{\mp} x$. Since $\mathcal{F} \subset C_{n}$ and $x_{n+1}=P_{C_{n}} x$, we have that

$$
\left\|x_{n+1}-x\right\| \leq\|p-x\|
$$

for all $n \geq 0$. Hence $\left\{x_{n}\right\}$ is bounded.

(II) Now we prove that $\left\|x_{n}-T_{i} x_{n}\right\| \rightarrow 0$ as $n \rightarrow \infty$ for all $i \in\{1,2, \ldots, N\}$.

Since $x_{n+1} \in C_{n}$, there exist some positive integer $m \in \mathbb{N}$ ( $\mathbb{N}$ denotes the set of all positive integers), $\left\{\mu_{i}\right\} \in \Delta^{m}$ and $\left\{z_{i}\right\}_{i=0}^{m} \subset C$ such that

$$
\begin{gathered}
\left\|x_{n+1}-\sum_{j=0}^{m} \mu_{j} z_{j}\right\|<t_{n}, \\
\sum_{i=1}^{N}\left\|z_{j}-T_{i} z_{j}\right\| \leq t_{n}\left\|x_{n}-y_{n}\right\|
\end{gathered}
$$


for all $j \in\{0,1, \ldots, m\}$. Put $r_{0}=\sup _{n \geq 1}\left\|x_{n}-p\right\|$ and $\lambda=\min _{1 \leq i \leq N}\left\{\lambda_{i}\right\}$. Take $\alpha \in(0,1) \cap$ $\left(0, \lambda / K^{2}\right]$. It follows from Lemma 2.2 and (3.5) that

$$
\begin{aligned}
\| x_{n}- & T_{i} x_{n}\left\|=\frac{1}{\alpha}\right\|\left(T_{i \alpha} x_{n}-p\right)+\left(p-x_{n}\right) \| \leq \frac{2 r_{0}}{\alpha} \\
\left\|T_{i}\left(\sum_{j=0}^{m} \mu_{j} z_{j}\right)-T_{i} x_{n+1}\right\| & \leq \frac{1}{\alpha}\left(\left\|T_{i \alpha}\left(\sum_{j=0}^{m} \mu_{j} z_{j}\right)-T_{i \alpha} x_{n+1}\right\|+(1-\alpha)\left\|\sum_{j=0}^{m} \mu_{j} z_{j}-x_{n+1}\right\|\right) \\
& \leq\left(\frac{2}{\alpha}-1\right)\left\|\sum_{j=0}^{m} \mu_{j} z_{j}-x_{n+1}\right\| \\
& \leq\left(\frac{2}{\alpha}-1\right) t_{n}
\end{aligned}
$$

for all $i \in\{1,2, \ldots, N\}$. Moreover, (3.7) implies

$$
\left\|x_{n}-y_{n}\right\| \leq \frac{2 r_{0}}{\alpha}
$$

It follows from Lemma 3.1, (3.5)-(3.9) that

$$
\begin{aligned}
& \sum_{i=1}^{N}\left\|x_{n+1}-T_{i} x_{n+1}\right\| \leq \sum_{i=1}^{N}\left(\left\|x_{n+1}-\sum_{j=0}^{m} \mu_{j} z_{j}\right\|+\left\|\sum_{j=0}^{m} \mu_{j}\left(z_{j}-T_{i} z_{j}\right)\right\|\right. \\
&\left.+\left\|\sum_{j=0}^{m} \mu_{j} T_{i} z_{j}-T_{i}\left(\sum_{j=0}^{m} \mu_{j} z_{j}\right)\right\|+\left\|T_{i}\left(\sum_{j=0}^{m} \mu_{j} z_{j}\right)-T_{i} x_{n+1}\right\|\right) \\
& \leq \frac{2 N}{\alpha}\left\|x_{n+1}-\sum_{j=0}^{m} \mu_{j} z_{j}\right\|+\sum_{j=0}^{m} \mu_{j}\left(\sum_{i=1}^{N}\left\|z_{j}-T_{i} z_{j}\right\|\right) \\
&+\sum_{i=1}^{N}\left\|\sum_{j=0}^{m} \mu_{j} T_{i} z_{j}-T_{i}\left(\sum_{j=0}^{m} \mu_{j} z_{j}\right)\right\| \\
& \leq \frac{2 N}{\alpha} t_{n}+t_{n}\left\|y_{n}-x_{n}\right\|+\sum_{i=1}^{N} \frac{1}{\alpha} \gamma^{-1}\left(\alpha \underset{0 \leq k<j \leq m}{\longrightarrow}\left(\left\|z_{k}-T_{i} z_{k}\right\|+\left\|z_{j}-T_{i} z_{j}\right\|\right)\right) \\
& \leq \frac{2 N+2 r_{0}}{\alpha} t_{n}+\frac{N}{\alpha} \gamma^{-1}\left(4 r_{0} t_{n}\right) \longrightarrow 0 \quad \text { as } n \longrightarrow \infty \\
&\left\|x_{n}-T_{i} x_{n}\right\| \longrightarrow 0 \quad \text { as } n \longrightarrow \infty
\end{aligned}
$$

This shows that

for all $i \in\{1,2, \ldots, N\}$.

(III) Finally, we prove that $x_{n} \rightarrow p=P_{\mp} x$. 
It follows from the boundedness of $\left\{x_{n}\right\}$ that there exists $\left\{x_{n_{i}}\right\} \subset\left\{x_{n}\right\}$ such that $x_{n_{i}} \rightarrow$ $v$ as $i \rightarrow \infty$. Since for each $i \in\{0,1, \ldots, N\}, T_{i}$ is a $\lambda_{i}$-strict pseudocontraction, then $T_{i}$ is demiclosed. one has $v \in \mathcal{F}$.

From the weakly lower semicontinuity of the norm and (3.4), we have

$$
\begin{aligned}
\|p-x\| & \leq\|v-x\| \leq \liminf _{i \rightarrow \infty}\left\|x_{n_{i}}\right\|-x \\
& \leq \limsup _{i \rightarrow \infty}\left\|x_{n_{i}}-x\right\| \leq\|p-x\| .
\end{aligned}
$$

This shows $p=v$ and hence $x_{n_{i}} \rightarrow p$ as $i \rightarrow \infty$. Therefore, we obtain $x_{n} \rightarrow p$. Further, we have that

$$
\lim _{n \rightarrow \infty}\left\|x_{n}-x\right\|=\|p-x\|
$$

Since $E$ is uniformly convex, we have $x_{n}-x \rightarrow p-x$. This shows that $x_{n} \rightarrow p$. This completes the proof.

Corollary 3.3. Let $C$ be a nonempty closed subset of a uniformly convex and 2-uniformly smooth Banach space $E$ with the best smooth constant $K>0$, assume that $T: C \rightarrow C$ is a $\lambda$-strict pseudocontraction for some $0<\lambda<1$ such that $\mathcal{F}(T) \neq \emptyset$. Let $\left\{x_{n}\right\}$ be a sequence generated by

$$
\begin{gathered}
x_{0}=x \in C, \\
C_{n}=\overline{\mathrm{co}}\left\{z \in C:\|z-T z\| \leq t_{n}\left\|x_{n}-T x_{n}\right\|\right\} \\
x_{n+1}=P_{C_{n}} x, \quad n=0,1,2, \ldots
\end{gathered}
$$

where $\left\{t_{n}\right\}$ is a sequence in $(0,1)$ with $t_{n} \rightarrow 0 . \overline{\mathrm{co}}\left\{z \in C:\|z-T z\| \leq t_{n}\left\|x_{n}-T x_{n}\right\|\right\}$ denotes the convex closure of the set $\left\{z \in C:\|z-T z\| \leq t_{n}\left\|x_{n}-T x_{n}\right\|\right\}$ and $P_{C_{n}}$ is the metric projection from $E$ onto $C_{n}$. Then $\left\{x_{n}\right\}$ converges strongly to $P_{\mathscr{f}(T)} x$.

Proof. Set $T_{1}=T, T_{k}=I$ for all $2 \leq k \leq N$, and $\alpha_{n, 1}=1, \alpha_{n, k}=0$ for all $2 \leq k \leq N$ in Theorem 3.2. The desired result can be obtained directly from Theorem 3.2.

Remark 3.4. At the end of the paper, we would like to point out that concerning the convergence problem of iterative sequences for strictly pseudocontractive mappings has been considered and studied by many authors. It can be consulted the references [24-37].

\section{Acknowledgment}

The authors would like to express their thanks to the referees for their valuable suggestions and comments. This work is supported by the Scientific Research Fund of Sichuan Provincial Education Department (11ZA221) and the Scientific Research Fund of Science Technology Department of Sichuan Province 2011JYZ010. 


\section{References}

[1] F. E. Browder and W. V. Petryshyn, "Construction of fixed points of nonlinear mappings in Hilbert spaces," Journal of Mathematical Analysis and Applications, vol. 20, pp. 197-228, 1967.

[2] F. E. Browder, "Fixed-point theorems for noncompact mappings in Hilbert space," Proceedings of the National Academy of Sciences of the United States of America, vol. 53, pp. 1272-1276, 1965.

[3] F. E. Browder, "Convergence of approximants to fixed points of nonexpansive nonlinear mappings in Banach spaces," Archive for Rational Mechanics and Analysis, vol. 24, pp. 82-90, 1967.

[4] R. E. Bruck," "Nonexpansive projections on subsets of Banach spaces," Pacific Journal of Mathematics, vol. 47, pp. 341-355, 1973.

[5] C. E. Chidume and S. A. Mutangadura, "An example on the Mann iteration method for Lipschitz pseudo-contractions," Proceedings of the American Mathematical Society, vol. 129, pp. 2359-2363, 2001.

[6] K. Deimling, "Zeros of accretive operators," Manuscripta Mathematica, vol. 13, pp. 365-374, 1974.

[7] K. Goebel and S. Reich, Uniform Convexity, Hyperbolic Geometry, and Nonexpansive Mappings, Marcel Dekker, New York, NY, USA, 1984.

[8] J. P. Gossez and E. L. Dozo, "Some geometric properties related to the fixed point theory for nonexpansive mappings," Pacific Journal of Mathematics, vol. 40, pp. 565-573, 1972.

[9] S. Reich, "Weak convergence theorems for nonexpansive mappings in Banach spaces," Journal of Mathematical Analysis and Applications, vol. 67, no. 2, pp. 274-276, 1979.

[10] T.-H. Kim and H.-K. Xu, "Strong convergence of modified Mann iterations," Nonlinear Analysis. Theory, Methods \& Applications, vol. 61, no. 1-2, pp. 51-60, 2005.

[11] H. Zhou, "Convergence theorems for $\lambda_{i}$-strict pseudo-contractions in 2-uniformly smooth Banach spaces," Nonlinear Anal, vol. 69, pp. 3160-3173, 2008.

[12] K. Nakajo and W. Takahashi, "Strong convergence theorems for nonexpansive mappings and nonexpansive semigroups," Journal of Mathematical Analysis and Applications, vol. 279, no. 2, pp. 372$379,2003$.

[13] H.-K. Xu, "Strong convergence of approximating fixed point sequences for nonexpansive mappings," Bulletin of the Australian Mathematical Society, vol. 74, no. 1, pp. 143-151, 2006.

[14] S.-y. Matsushita and W. Takahashi, "Approximating fixed points of nonexpansive mappings in a Banach space by metric projections," Applied Mathematics and Computation, vol. 196, no. 1, pp. 422 425, 2008.

[15] S. M. Kang and S. Wang, "New hybrid algorithms for nonexpansive mappings in Banach spaces," International Journal of Mathematical Analysis, vol. 5, no. 9-12, pp. 433-440, 2011.

[16] I. Cioranescu, Geometry of Banach Spaces, Duality Mappings and Nonlinear Problems, vol. 62 of Mathematics and Its Applications, Kluwer Academic Publishers, Dordrechtm The Netherlands, 1990.

[17] Y. I. Alber, "Metric and generalized projection operators in Banach spaces: properties and applications," in Theory and Applications of Nonlinear Operators of Accretive and Monotone Type, vol. 178 of Lecture Notes in Pure and Applied Mathematics, pp. 15-50, Marcel Dekker, New York, NY, USA, 1996.

[18] W. Takahashi, Nonlinear Functional Analysis, Fixed Point Theory and Its Applications, Yokohama Publishers, Yokohama, Japan, 2000.

[19] F. E. Browder, "Convergence theorems for sequences of nonlinear operators in Banach spaces," Mathematische Zeitschrift, vol. 100, pp. 201-225, 1967.

[20] D. Pascali and S. Sburlan, Nonlinear Mappings of Monotone Type, Noordhoff, Leyden, The Netherlands, 1978.

[21] H. K. Xu, "Inequalities in Banach spaces with applications," Nonlinear Analysis, vol. 16, pp. 1127-1138, 1991.

[22] H. Zhou, "Convergence theorems of common fixed points for a finite family of Lipschitz pseudocontractions in Banach spaces," Nonlinear Analysis: Theory, Methods and Applications, vol. 68, no. 10, pp. 2977-2983, 2008.

[23] R. E. Bruck, "On the convex approximation property and the asymptotic behavior of nonlinear contractions in Banach spaces," Israel Journal of Mathematics, vol. 38, no. 4, pp. 304-314, 1981.

[24] Y. Su, M. Li, and H. Zhang, "New monotone hybrid algorithm for hemi-relatively nonexpansive mappings and maximal monotone operators," Applied Mathematics and Computation, vol. 217, no. 12, pp. 5458-5465, 2011.

[25] S. S. Chang, H. W. J. Lee, C. K. Chan, and J. K. Kim, "Approximating solutions of variational inequalities for asymptotically nonexpansive mappings," Applied Mathematics and Computation, vol. 212, no. 1, pp. 51-59, 2009. 
[26] H. Zegeye and N. Shahzad, “Convergence of Mann's type iteration method for generalized asymptotically nonexpansive mappings," Computers $\mathcal{E}$ Mathematics with Applications, vol. 62, no. 11, pp. 4007-4014, 2011.

[27] X. Qin, S. Huang, and T. Wang, "On the convergence of hybrid projection algorithms for asymptotically quasi-nonexpansive mappings," Computers \& Mathematics with Applications, vol. 61, no. 4, pp. 851-859, 2011.

[28] S.-s. Chang, L. Wang, Y.-K. Tang, B. Wang, and L.-J. Qin, "Strong convergence theorems for a countable family of quasi- $\phi$-asymptotically nonexpansive nonself mappings," Applied Mathematics and Computation, vol. 218, no. 15, pp. 7864-7870, 2012.

[29] W. Nilsrakoo, "Halpern-type iterations for strongly relatively nonexpansive mappings in Banach spaces," Computers $\mathcal{E}$ Mathematics with Applications, vol. 62, no. 12, pp. 4656-4666, 2011.

[30] S.-S. Chang, H. W. J. Lee, C. K. Chan, and J. A. Liu, "Strong convergence theorems for countable families of asymptotically relatively nonexpansive mappings with applications," Applied Mathematics and Computation, vol. 218, no. 7, pp. 3187-3198, 2011.

[31] W. Nilsrakoo and S. Saejung, "Strong convergence theorems by Halpern-Mann iterations for relatively nonexpansive mappings in Banach spaces," Applied Mathematics and Computation, vol. 217, no. 14, pp. 6577-6586, 2011.

[32] S. Suantai, W. Cholamjiak, and P. Cholamjiak, "An implicit iteration process for solving a fixed point problem of a finite family of multi-valued mappings in Banach spaces," Applied Mathematics Letters, vol. 25, no. 11, pp. 1656-1660, 2012.

[33] S. S. Chang, K. K. Tan, H. W. J. Lee, and C. K. Chan, "On the convergence of implicit iteration process with error for a finite family of asymptotically nonexpansive mappings," Journal of Mathematical Analysis and Applications, vol. 313, no. 1, pp. 273-283, 2006.

[34] S. S. Chang, H. W. J. Lee, C. K. Chan, and W. B. Zhang, "A modified halpern-type iteration algorithm for totally quasi- $\phi$-asymptotically nonexpansive mappings with applications," Applied Mathematics and Computation, vol. 218, no. 11, pp. 6489-6497, 2012.

[35] X. Qin, S. Y. Cho, and S. M. Kang, "Strong convergence of shrinking projection methods for quasi- $\phi-$ nonexpansive mappings and equilibrium problems," Journal of Computational and Applied Mathematics, vol. 234, no. 3, pp. 750-760, 2010.

[36] D. Wu, S.-s. Chang, and G. X. Yuan, "Approximation of common fixed points for a family of finite nonexpansive mappings in Banach space," Nonlinear Analysis. Theory, Methods E Applications, vol. 63, no. 5-7, pp. 987-999, 2005.

[37] C. Zhang, J. Li, and B. Liu, "Strong convergence theorems for equilibrium problems and relatively nonexpansive mappings in Banach spaces," Computers \& Mathematics with Applications, vol. 61, no. 2, pp. 262-276, 2011. 


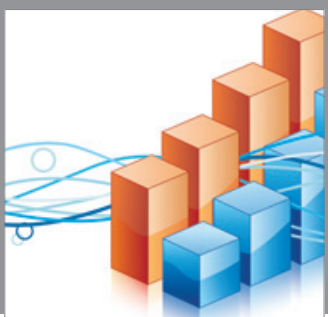

Advances in

Operations Research

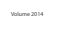

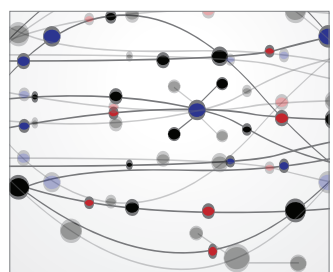

\section{The Scientific} World Journal
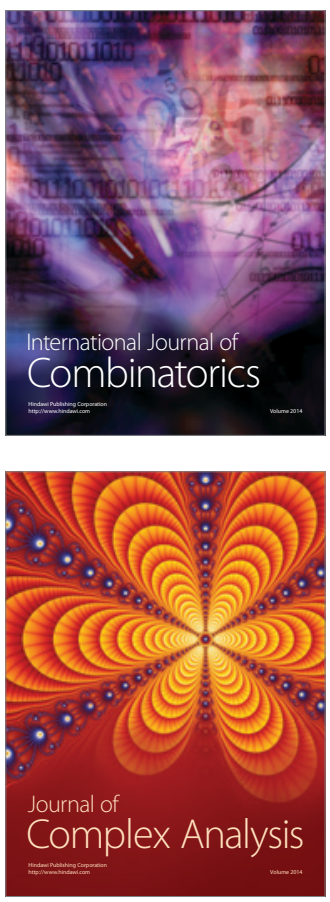

International Journal of

Mathematics and

Mathematical

Sciences
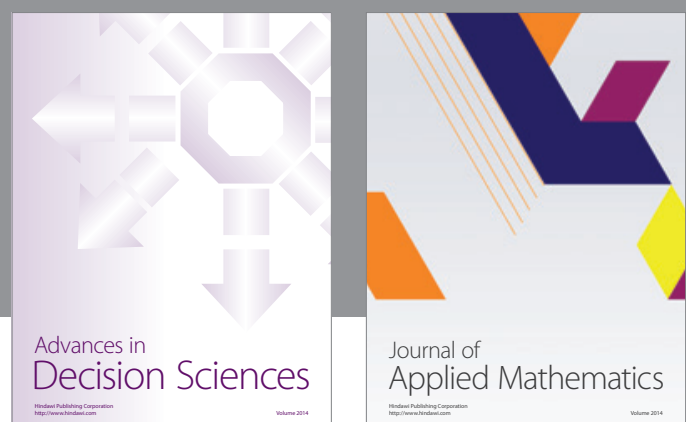

Journal of

Applied Mathematics
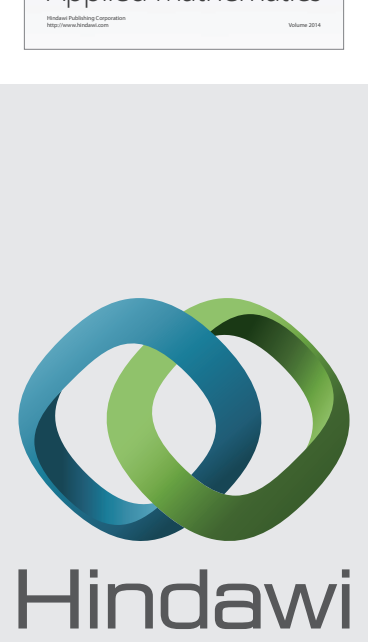

Submit your manuscripts at http://www.hindawi.com
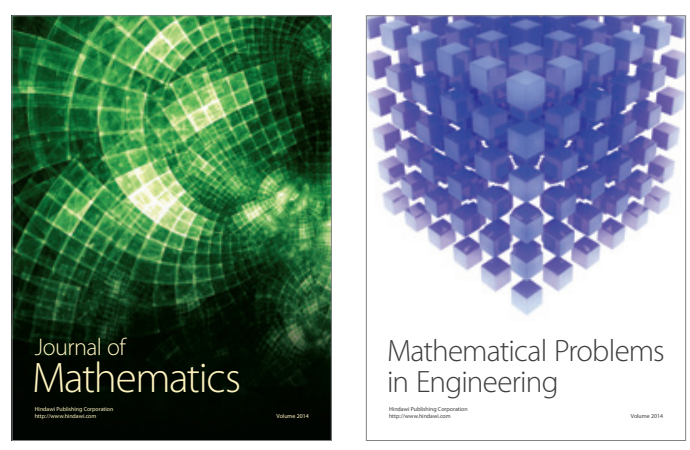

Mathematical Problems in Engineering
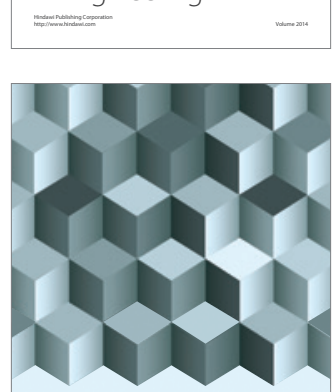

Journal of

Function Spaces
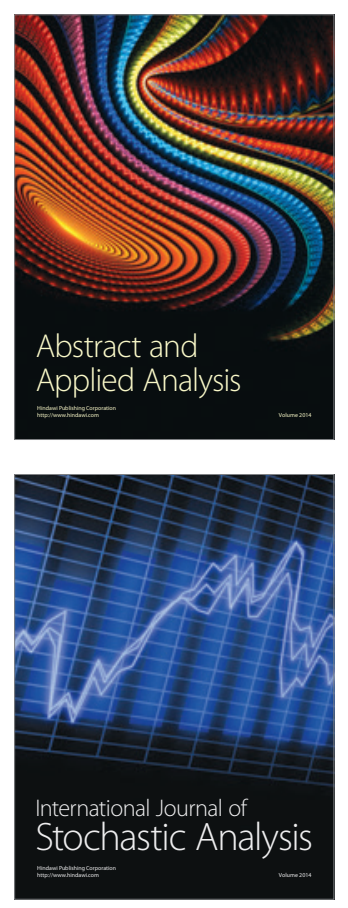

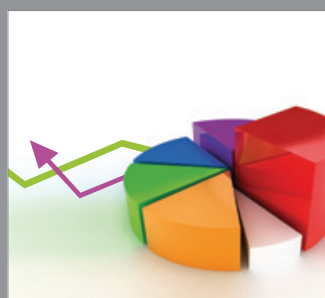

ournal of

Probability and Statistics

Promensencen
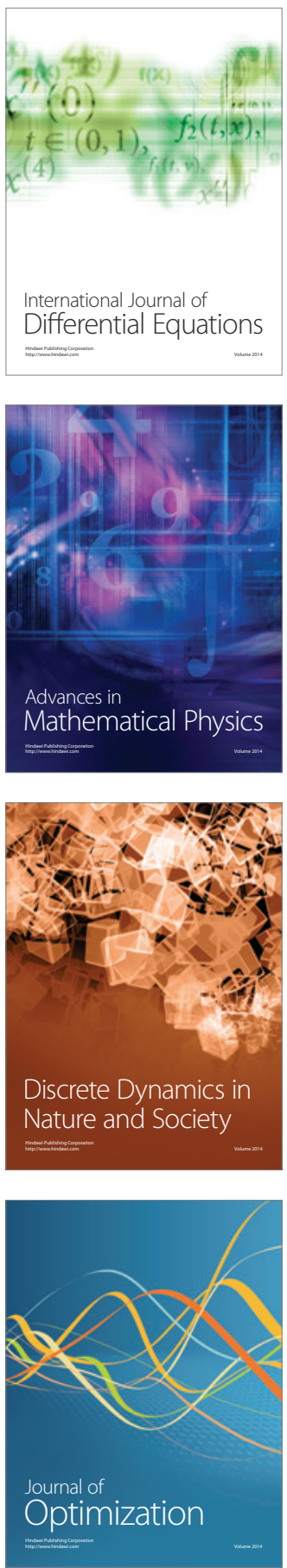